\title{
Efficacy of continuous femoral three-in-one nerve block using stimulating nerve catheter and non stimulating nerve catheter for postoperative analgesia in surgeries over thigh: a comparative study
}

\author{
Alpa Patel ${ }^{1}$, Nitin Choudhary ${ }^{2, *}$, Utpala Kharod ${ }^{3}$, Vikas $^{4}$ \\ ${ }^{1}$ Professor and HOD, ${ }^{2}$ Senior Resident, ${ }^{3}$ Dean \& Professor, ${ }^{4}$ Ex-PG Student, Dept. of Anaesthesiology, ${ }^{1,3,4}$ Pramukhswami \\ Medical College, Gujarat, ${ }^{2}$ Maulana Azad Medical College, Delhi, India
}

*Corresponding Author: Nitin Choudhary

Email: drnitinchoudhary@yahoo.in

Received: $14^{\text {th }}$ May, 2017

Accepted: $17^{\text {th }}$ April, 2018

\begin{abstract}
Introduction: Continuous femoral analgesia provides extended pain relief for surgeries over thigh. Successful continuous peripheral nerve analgesia depends on catheter proximity to the target nerve and stimulating catheters may allow more accurate placement of catheters. Hence we conducted a study to compare the efficacy of stimulating nerve catheter and non stimulating nerve catheter in femoral 3-in-1 nerve block for postoperative analgesia.

Materials and Methods: 60 ASA grade I \& II patients of either sex between 18 to 65 years of age posted for total knee replacement surgery were randomly allocated into two groups: Group SC (stimulating catheter) and Group NSC(non stimulating catheter). All patients received subarachnoid block and after completion of surgery femoral catheter (stimulating/non stimulating depending on the group) was placed using peripheral nerve stimulator for postoperative analgesia. When spinal level regressed to T12 dermatomal level, Inj.Bupivacaine $(0.25 \%) 20 \mathrm{ml}$ with Inj.Lignocaine (1\%) $10 \mathrm{ml}$ was given. The patients were followed for next 24 hours from the time of first bolus. After the $1^{\text {st }}$ bolus when the VRS score was $\geq 3$, intermittent boluses of Inj.Bupivacaine (0.25\%) $15 \mathrm{ml}$ with Inj.Fentanyl $0.5 \mu \mathrm{g} / \mathrm{kg}$ were given. All patients received Inj. Paracetamol $20 \mathrm{mg} / \mathrm{kg}$ IV 6 hourly. In case patient still had VRS score $\geq 3$ then rescue analgesia in the form of Inj.Diclofenac sodium $1 \mathrm{mg} / \mathrm{kg}$ IV was given. Two groups were observed for total duration of sensory block (time from 1st bolus dose till the time VAS score was $\geq 3$ ); requirement of analgesic solution; requirement of rescue analgesia; and any complication or side effects.

Results: Total duration of sensory block in group SC was $9.40 \pm 0.21$ hours compared to $7.10 \pm 0.23$ hours in group NSC $(\mathrm{p}=0.0001)$. Total requirement of analgesic solution was less in SC group in comparison to NSC group. No significant complication observed in either group.

Conclusion: Stimulating nerve catheter provides longer duration of sensory blockade with decreased requirement of local anaesthetic solution and opioid when compared to non stimulating nerve catheter.
\end{abstract}

Keywords: Continuous femoral three-in-one nerve block, Stimulating catheter, Non stimulating catheter, Postoperative analgesia.

\section{Introduction}

Pain is considered to be the fifth vital sign and is an important variable in assessing the postoperative morbidity in patients. Postoperative pain relief plays an important role by providing comfort to the anxious patients; improved morale and mobility contributing to a more rapid and complete recovery; decreasing the incidence of pulmonary complications and by reducing the incidence of thromboembolic phenomenon. If pain is not treated in immediate postoperative period, it may lead to adverse physiological, psychological responses, delayed recovery and chronic pain.

The methods of controlling pain after orthopaedic surgery include systemic medications, intravenous patient controlled analgesia, central neuraxial blockade and peripheral nerve blocks. Continuous femoral threein-one nerve block is effective method used to provide postoperative analgesia with fewer side effects and accelerated functional recovery after major orthopaedic surgery.

When performing continuous nerve block using nerve using peripheral nerve stimulator, efforts are made to place the catheter close to the nerve to achieve effective perioperative analgesia. Secondary analgesic block failure rate with this technique are high. However in case of insufficient block, the catheters cannot be redirected. To overcome this limitation, stimulating nerve catheters were introduced which can be stimulated using a peripheral nerve stimulator after threading through the needle and its position can be adjusted and subsequently verified for proper placement, reducing the chances of secondary block failure.

We undertook this study to evaluate the efficacy of stimulating and non stimulating nerve catheter in continuous femoral three-in-one block with regards to duration of sensory blockade, total requirement of analgesic solution (local anaesthetic solution and opioid), requirement of rescue analgesic in postoperative period, mean VRS score and hemodynamic stability and any complications or side effects. 


\section{Materials and Methods}

A prospective randomised single blinded controlled study of 60 patients was carried out in the department of anaesthesiology of a tertiary care hospital. Before starting the study, approval from after the institutional ethics committee was taken. Patients of ASA I-II physical status between ages 18-65 years of either sex, to be operated for surgeries over thigh were enrolled for the study.

Patients having local site infection, deranged coagulation profile, hypotension, uncontrolled diabetes mellitus, uncontrolled hypertension, acute or chronic respiratory disease, presence of femoral vascular graft, hypersensitivity to local anaesthetic solution, cognitive or psychiatric disturbances, pre-existing neuropathy were not included in the study.

All patients underwent thorough pre-anaesthetic check up. Routine laboratory investigations and special investigations if required were done. The anaesthetic procedure to be carried out was explained and the patients were reassured to alleviate their anxiety. They were educated regarding verbal rating scale (VRS) for pain. A prior written and informed consent was taken from all patients. All patients were kept nil per oral as per standard ASA guidelines. Patients did not receive any premedication. Based on the computer generated randomization table, the patients were randomly divided into one of the following groups as follows:

Group NSC- Non stimulating catheter

Group SC- Stimulating catheter

The patient was shifted to operation theatre and standard ASA monitors namely ECG, $\mathrm{SpO}_{2}$ and NIBP were attached. IV line was secured and Inj.Ringer Lactate or Inj.Normal Saline was started. Under all aseptic and antiseptic precautions spinal anaesthesia was administered to the patient. No adjuvant was added to the local anaesthetic given in spinal anaesthesia. Surgery was conducted under spinal anaesthesia.

After the completion of surgery, patient was prepared for continuous femoral nerve block. The block was performed in supine position. A line was drawn between the anterior superior iliac spine and the pubic tubercle which corresponds to the inguinal ligament. The femoral artery was identified at the mid-point of the inguinal ligament after feeling its pulsation and it was marked. Sterile painting and draping was done. A stimulating needle was inserted $1.5 \mathrm{~cm}$ lateral to the arterial pulsation at an angle of $35-45^{\circ}$ to the vertical plane. The needle tip was stimulated with the help of nerve stimulator and elicitation of contraction of quadriceps femoris muscle with a current of $0.4-0.5 \mathrm{~mA}$ at $0.1 \mathrm{~ms}$ was considered as satisfactory needle position.

In group NSC, a non stimulating catheter was threaded through the needle for a distance of $5 \mathrm{~cm}$ from the needle tip. The catheter was fixed to the skin and proper sterile dressing was applied.
In group SC, a stimulating nerve catheter was threaded through the needle and electrical stimulation was applied to the catheter to obtain satisfactory catheter placement. Contractions of the quadriceps femoris muscle with a current of $\leq 0.7 \mathrm{~mA}$ at $0.1 \mathrm{~ms}$ was accepted as proper catheter placement. This current was selected to prevent nerve damage caused by multiple manipulation of the stimulating catheter to obtain contractions with a lower current value. After confirming the catheter position, the position of catheter at the level of skin was noted and the catheter was fixed to the skin and proper sterile dressing was applied.

After the procedure was over, the patient was shifted to post anaesthesia care unit (PACU). In PACU, the level of the sensory block was assessed periodically and when the sensory level regressed to T12 dermatomal level, bolus dose of local anaesthetic consisting of Inj. Bupivacaine $0.25 \% 20 \mathrm{ml}+$ Inj. Lignocaine $1 \% 10 \mathrm{ml}$ was given, a total of $30 \mathrm{ml}$ was given after ensuring negative aspiration via the continuous femoral nerve catheter. Patient was shifted to ward and was observed for pain, any complication or side effect. Pain was assessed on verbal rating scale (VRS) every one hourly for first 2 hours followed by two hourly for next 12 hours and then four hourly for till 24 hours postoperatively. If $\mathrm{VRS} \geq 3$, top-up was given via catheter in the form of Inj.Bupivacaine $0.25 \%$ $15 \mathrm{ml}+$ Inj.Fentanyl $0.5 \mu \mathrm{g} / \mathrm{kg}$. Lock out interval of at least 4 hours was observed between two consecutive top-ups. If $\mathrm{VRS} \geq 3$ between the lockout interval period, rescue analgesic in the form of Inj.Diclofenac Sodium $1 \mathrm{mg} / \mathrm{kg}$ IV was given. Inj. Diclofenac Sodium was not repeated more than 8 hourly. All patients received Inj. Paracetamol $20 \mathrm{mg} / \mathrm{kg}$ IV 6 hourly as a part of multimodal analgesia regimen. Patients were observed for 24 hours postoperatively. The incidence of side effects such as nausea, vomiting, shivering, itching, pruritus, respiratory depression, sedation, hypotension and symptoms of local anaesthetic toxicity were recorded. Nausea/vomiting were treated with Injection Ondansetron $4 \mathrm{mg}$ IV. Hypotension was treated with intravenous fluids and/or injection mephentermine $6 \mathrm{mg}$ IV bolus. Bradycardia was treated with Injection Atropine $0.6 \mathrm{mg}$ IV. Pruritus was treated with Injection Promethazine $25 \mathrm{mg}$ IM which was repeated after 1 hour if needed. Oxygen by Hudson mask was provided if $\mathrm{SpO}_{2}$ decreased to $<94 \%$. Injection naloxone (in dose of 0.1-0.2 $\mathrm{mg}$ IV bolus, to be repeated as needed every 3-4 min) was reserved for patients with respiratory rate $<8 / \mathrm{min}$. In case of inadvertent arterial puncture, adequate compression was applied at the site for 5 minutes and the procedure was repeated again. In case of arterial puncture for the second time, the procedure was abandoned and compression bandage was applied after 5 minutes of compression.

The two groups were compared with respect to: 
1. Total duration of sensory blockade: It was defined as the total time duration between the bolus injection and the first top-up

2. Total amount of local anaesthetic solution $\mathrm{n}$ consumed in 24 hours

3. Total amount of opioid( Inj. Fentanyl) consumed in 24 hours

4. Total number of doses of rescue analgesic given in 24 hours (Inj. Diclofenac Sodium)

5. Any complication or side effects

\section{Statistical Analysis}

Data obtained were tabulated and analyzed using Statistical Package for Social Science (SPSS 11.0 evaluation version). Data was expressed as means and standard deviation (SD), medians and ranges, or numbers and percentages. For categorical covariates (sex, ASA class, nausea/vomiting, use of rescue analgesia, hypotension, and bradycardia) Chi-square test or Fisher's exact test was used as appropriate, with $P$ value reported at the $95 \%$ confidence interval (CI).

\section{Results}

We studied total 60 patients between the ages of 18 to 65 years, 30 patients per group. There was no secondary block failure.

The demographic data like age, sex, weight, and type of surgeries were comparable between Group NSC and Group SC (Table 1).

Table 1

\begin{tabular}{|l|c|c|c|}
\hline \multicolumn{1}{|c|}{ Parameter } & Group NSC & Group SC & P Value \\
\hline Age(yrs) & $42.50 \pm 3.80$ & $48.65 \pm 4.53$ & 0.305 \\
\hline Weight $(\mathrm{kg})$ & $54.85 \pm 1.40$ & $53.25 \pm 1.46$ & 0.435 \\
\hline
\end{tabular}

The mean duration of the sensory blockade after the initial bolus dose was $7.10 \pm 0.23$ hours in group NSC and 9.40 \pm 0.21 hours in group SC which was significant clinically as well as statistically $(\mathrm{p}=0.00001)$.

The total amount of local anaesthetic solution consumption in group NSC was $62.50 \pm 1.72 \mathrm{ml}$ while in group SC it was $49.75 \pm 1.64 \mathrm{ml}$ which was statistically significant. The total amount of opioid consumption in group NSC was $165 \pm 7.34 \mathrm{mcg}$ while in group SC it was $115 \pm 5.26 \mathrm{mcg}$ which was statistically significant. (Table 2)

Table 2

\begin{tabular}{|l|c|c|c|}
\hline \multicolumn{1}{|c|}{ Parameter } & Group NSC & Group SC & P value \\
\hline Local anaesthetic solution(ml) & $62.50 \pm 1.72$ & $49.75 \pm 1.64$ & 0.0001 \\
\hline Amount of Opioid(mcg) & $165 \pm 7.34$ & $115 \pm 5.26$ & 0.0001 \\
\hline
\end{tabular}

The mean VRS score were compared between the two groups and it was found that the mean VRS score was lower in the SC group than the NSC group which was significant clinically as well as statistically.

The two groups were compared with respect to pulse rate, mean arterial pressure, respiratory rate and $\mathrm{SpO}_{2}$ and there was no statistically significant difference between the two groups.

The provision of rescue analgesia using Inj.Diclofenac sodium was kept for patients experiencing $\mathrm{VRS} \geq 3$ even after the administration of intermittent bolus drug. However no patient in either group required rescue analgesia.

There was only one incidence of inadvertent arterial puncture in group NSC which was managed by compression over the site for 5 minutes. The nerve was located on the second attempt successfully and the catheter threaded. No patient in group SC had any complication.

\section{Discussion}

Adequate postoperative pain relief contributes significantly to patient's comfort and recovery and also prevents adverse consequences of surgical insult. Patients undergoing orthopaedic surgeries need good intraoperative anaesthesia as well as postoperative analgesia. Central neeuraxial block is commonly used for providing surgical anaesthesia and postoperative analgesia for orthopaedic surgeries. Continuous threein-one block is the most commonly used peripheral nerve block technique for providing postoperative analgesia for surgeries over thigh, hip and knee. Antinociceptive synergism of opiods is proved to improve the quality and prolong the analgesic effect of the local anaesthetics.

The present study titled " Effects of continuous femoral three-in-one nerve block using stimulating nerve catheter and non stimulating nerve catheter for postoperative analgesia in surgeries over thigh: A comparative study" was undertaken in our hospital after approval from the institutional ethical committee. After complete preoperative examination, 60 patients of ASA I and II physical status between 18-65 yrs of either sex scheduled for elective orthopaedic surgery over thigh were included in the study. They were randomly divided into two groups of 30 patients each namely:

Group NSC- A non stimulating catheter was inserted using a peripheral nerve locator.

Group SC- A stimulating nerve catheter was inserted using a peripheral nerve locator and after catheter 
insertion, the catheter was stimulated to confirm proper positioning.

Both the groups were comparable to each other with respect to age, sex, weight, ASA physical status and the type of surgeries.

In our study it was not possible to assess the onset of sensory block in patients as they had received subarachnoid block for surgical procedure and at the time of insertion of femoral nerve catheters, the patients were already having sensory blockade due to the subarachnoid block. The sensory block in postoperative period was assessed by using pin prick method. The mean duration of sensory blockade after the initial bolus dose was $7.10 \pm 023$ hours in group NSC and $9.40 \pm 0.21$ hours in group SC. The mean duration of sensory block was longer in the SC group which significant clinically as well as statistically. However, the previous studies did not compare the duration of sensory block between stimulating and non stimulating nerve catheters.

In our study the mean VRS score was lower in SC group than the NSC group $(\mathrm{p}<0.05)$ which was statistically significant. It was contrary to the finding by N. T. M. Jack et $\mathrm{al}^{5}$ who found postoperative visual analogue scores similar in two groups during the first 24 hours. Salim M. Hayek et $\mathrm{al}^{2}$ also concluded no significant difference in the numeric pain rating scale scores between the two groups.

In our study there was lower requirement of local anaesthetic solution and opioid in stimulating nerve catheter than with non stimulating catheter group which was statistically significant. Salim M. Hayek et $\mathrm{al}^{2}$ found no statistically significant differences in the amount of ropivacaine administered; the median amount of ropivacaine given to patients in the stimulating catheter group was $8.2 \mathrm{ml} / \mathrm{h}$ vs. $8.8 \mathrm{ml} / \mathrm{h}$ for patients with non-stimulating catheters, $\mathrm{P}=0.26$.

In our study the provision of rescue analgesia with Inj. Diclofenac sodium was kept for patients experiencing pain (VRS>3) even after the administration of intermittent bolus drug. However none of the patients in the study required rescue analgesia. Our finding was consistent with those found by Salim M. Hayek et $\mathrm{al}^{2}$ with no significant differences between the treatment groups for the amount of fentanyl dispensed by the IVPCA. N. T. M. Jack et $\mathrm{al}^{5}$ did not find any difference in morphine consumption between the two groups.

In our study there was only one incidence of accidental arterial puncture in group NSC which was managed by compression at the site and the procedure was performed again successfully. There was no incidence of any side effects due to local anaesthetic solution or opioid in either group.

\section{Conclusion}

From the study it was observed that using stimulating nerve catheter for instituting three-in-one femoral nerve block provided longer duration of sensory blockade, decreased consumption of local anaesthetic and opioid, lower mean VRS scores with stable hemodynamic parameters and low incidence of complications as compared to non stimulating catheter. Stimulating catheters may have an important role in high risk surgical patients for which further studies need to be conducted.

Based on our study, the use of stimulating nerve cathters can be recommended in place of non stimulating nerve catheters for surgeries over the thigh in the studies age group of patients as it provides better pain relief with lower incidence of complications.

\section{Conflict of Interest: None}

\section{References}

1. Dauri M, Polzoni M, Fabbi E, Sidiropoulou T, Servetti S, Coniglione F, Mariani P, Sabato AF. Comparison of epidural, continuous femoral block and intraarticular analgesia after anterior cruciate ligament reconstruction. Acta Anaesthesiol Scand. 2003;47(1):20-25.

2. Salim M. Hayek, R. Michael Ritchey, Daniel Sessler, Robert Helfand, Samuel Samuel, Meng Xu, Michael Beven, Demetrios Bourdakos, Wael Barsoum, Peter Brooks. Continuous femoral nerve analgesia after unilateral total knee arthroplasty: stimulating versus non-stimulating catheters. Anesth Analog. 2006;103(6):1565-1570.

3. Petchara sundarathiti, jadesadha thammasakulsiri, supawadee supboon, supalak sakdanuwatwong, molruedee piangjai. Comparison of continuous femoral nerve block (CFNB/SA) and continuous femoral nerve block with mini-dose spinal morphine (CFNB/SAMQ) for postoperative analgesia after total knee arthroplasty (TKA): a randomized controlled study. $B M C$ Anesthesiol. 2016;16:38.

4. Ng FY, Chiu KY, Yan CH, Ng KF. Continuous femoral nerve block versus patient-controlled analgesia following total knee arthroplasty. J Ortho Surg(Hong Kong). 2012;20(1):23-26.

5. N. T. M. Jack, E. B. Liem, L. H. Vonhogen. Use of stimulating catheter for total knee replacement surgery: preliminary results. Br J Anaesth. 2005;95:250-254.

6. Salinas FV, Neal JM, Sueda LA, Kopacz DJ, Liu SS Prospective comparison of continuous femoral nerve block with nonstimulating catheter placement versus stimulating catheter-guided perinueral placement in volunteers. Reg Anaesth Pain Med. 2004;29:212-220.

7. Pham-Dang, Kick O, Collet T, Gouin F, Pinaud M. Continuous peripheral nerve blocks with stimulating catheters. Reg Anaesth Pain Med. 2003;28:83-88.

8. Singelyn FJ, Deyaert M, Joris D. Effects of intravenous patient-controlled analgesia with morphine, continuous epidural analgesia, and continuous three-in-one block on postoperative pain and knee rehabilitation after unilateral total knee arthroplasty. Anaesth Analg. 1998;87:88-92.

9. Capdevila X, Barthelet Y, Biboulet P. Effects of perioperative analgesic technique on the surgical outcome and duration of rehabilitation after major knee surgery. Anaesthesiol. 1999;91:8-15. 
10. Albrecht E, Morfey D, Chan V, Gandhi R, Koshkin A, Chin KJ, Robinson S, Frascarolo P, Brull R. Singleinjection or continuous femoral nerve block for total knee arthroplasty? Clin Orthop Relat Res.

2014;472(5):1384-1393.

How to cite this article: Patel A, Choudhary N, Kharod U, Vikas. Efficacy of continuous femoral three-in-one nerve block using stimulating nerve catheter and non stimulating nerve catheter for postoperative analgesia in surgeries over thigh: a comparative study. Indian J Clin Anaesth. 2018;5(4):556-560 